\title{
AGENDA 21 LOCAL: SUBSÍDIOS PARA A DISCUSSÃO DE TEMAS NA SUB-BACIA DO RIO SARACURUNA
}

\author{
Rodrigo Silva da Conceição'
}

\section{Liane Maria Azevedo Dornelles ${ }^{2}$}

Resumo: A Agenda 21 Local, instrumento em potencial para o planejamento de políticas públicas, pode ser elaborada a partir de um fórum de discussões estabelecido em qualquer arranjo territorial - como, por exemplo, uma sub-bacia hidrográfica. Este trabalho objetiva uma reflexão sobre uma futura Agenda 21 Local da sub-bacia do rio Saracuruna RJ a partir do exercício de fixação dos preceitos deste instrumento aplicado em âmbito local, favorável à integração de temas e atores sociais, considerando a visão de especialistas e não especialistas, disponível frente aos temas. A diversidade ambiental na sub-bacia do Saracuruna revela uma gama de problemáticas e potencialidades, culminando em uma riqueza de possibilidades a serem consideradas no levantamento dos temas prioritários de discussão, com ênfase para questões relacionadas às Áreas de Preservação Permanente (APP's). Neste sentido, este trabalho considerou o tema Ocupação de moradias em Áreas de Preservação Permanente como prioritário para análise exemplificativa.

Palavras-chave: Agenda 21 Local. Áreas de Preservação Permanente. Sub-bacia do rio Saracuruna - RJ.

\section{INTRODUÇÃO}

\footnotetext{
${ }^{1}$ Geógrafo, Doutorando em Meio Ambiente / Programa de Pós-Graduação em Meio Ambiente - UERJ. Email: rsc_geo@yahoo.com.br

${ }^{2}$ Geóloga, Doutora em Geografia (Universidade Federal do Rio de Janeiro) / Programa de Pós-Graduação em Meio Ambiente - UERJ. E-mail: lianedornelles@gmail.com
} 


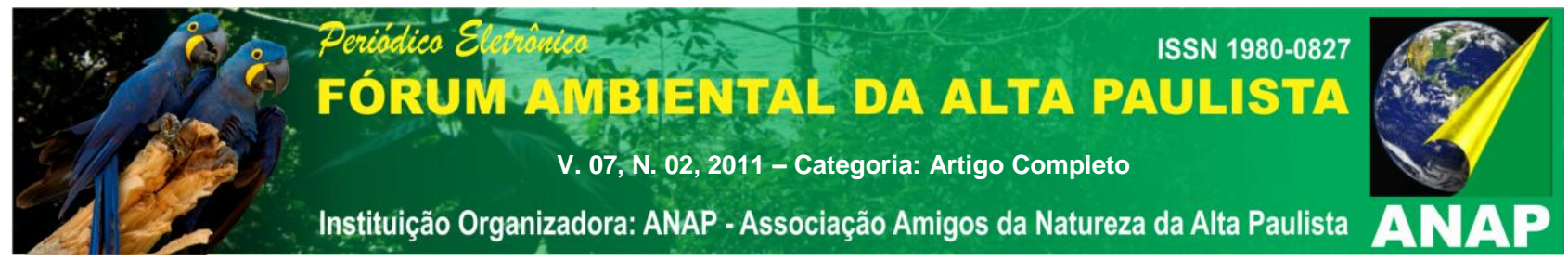

Nos últimos anos as discussões sobre as questões ambientais e planejamento do território têm avançado em uma perspectiva de integração e participação social. Um grande marco neste processo se refere à realização da segunda Conferência Mundial para o Meio Ambiente e Desenvolvimento (ECO - 92), na qual um dos seus resultados mais importantes foi a formulação do documento da Agenda 21, com estratégias de cooperação que devem ser adotadas para a sustentabilidade (ABIRACHED, 2006; ROSA, 2007).

A Agenda 21 Local deve ser entendida como um instrumento de planejamento de políticas públicas que envolve tanto a sociedade civil e o governo em um processo amplo e participativo de consulta sobre problemas de diversas ordens - ambientais, sociais e econômicos -, no âmbito local. Neste processo consta ainda o debate sobre soluções para esses problemas através da identificação e implementação de ações concretas com sustentabilidade local (MMA, 2010).

Com base nisto, este trabalho visa explorar o tema Ocupação de moradias em Áreas de Preservação Permanente vinculado a uma futura Agenda 21 Local da sub-bacia do rio Saracuruna - RJ, considerando a ligação deste com outros prováveis temas, além da avaliação das visões de especialistas e não especialistas, e suas possíveis repercussões no âmbito do instrumento.

\section{DESENVOLVIMENTO}

\subsection{AGENDA 21 LOCAL EM SUB-BACIAS}

A Agenda 21 Local pode ser construída e implementada, a partir de um fórum de discussões, em municípios, bairros ou em quaisquer outros arranjos territoriais - como bacias hidrográficas, por exemplo.

Segundo Abirached (2006), os municípios podem criar todas as condições para implantar uma Agenda 21 Local, a fim de definir, por meio de processo de planejamento 


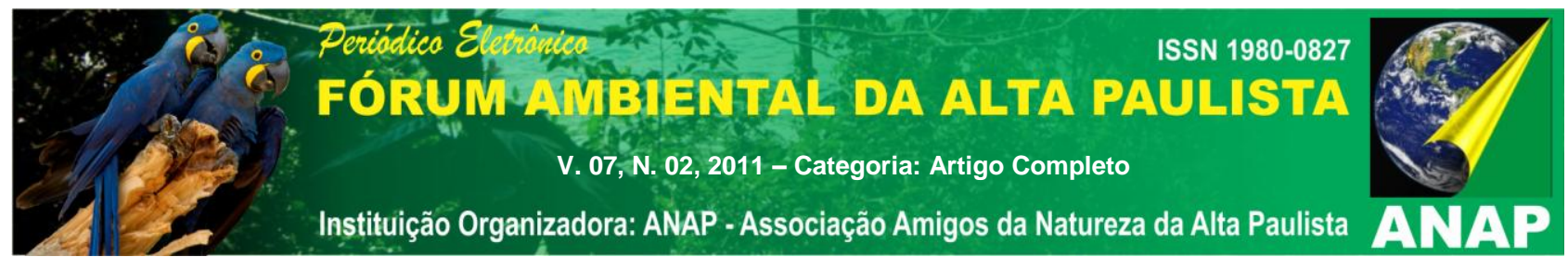

participativo, um modelo de desenvolvimento local em bases sustentáveis e que leve em consideração o recorte territorial de bacia hidrográfica.

Uma bacia hidrográfica pode ser entendida como um conjunto de terras drenado por um rio principal e seus afluentes. Segundo Cunha e Coelho (2003, p. 70) "a bacia é uma realidade física, mas é também um conceito socialmente construído". Os autores ainda complementam que a bacia hidrográfica:

\begin{abstract}
Passa a ser um campo de ação política, de partilha de responsabilidade e de tomada de decisões. Problemas como desmatamento, mudanças microclimáticas, contaminação dos rios, erosão, enchentes e tensões físico-sociais de natureza diversa impuseram a necessidade de cooperação entre diferentes esferas administrativas.
\end{abstract}

As sub-bacias, inseridas em uma região hidrográfica, podem ser consideradas compartimentos para o gerenciamento ambiental, possibilitando o monitoramento hidrológico, a conservação do solo e a disciplina do uso da terra (CASTRO DA COSTA, et. al.).

\title{
2.2 SUB-BACIA DO RIO SARACURUNA - RJ
}

Conforme informações do Instituto da Baía de Guanabara (IBG, 2002), um dos rios mais importantes da Região Hidrográfica da Baía de Guanabara e dos Sistemas Lagunares de Maricá e Jacarepaguá, no Estado do Rio de Janeiro, é o Saracuruna. O mesmo corta totalmente o município de Duque de Caxias (é considerado um rio municipal), e possui diversos tributários, que cortam parcialmente municípios vizinhos.

O rio Saracuruna nasce na Serra do Mar em uma altitude acima dos 1.000 metros, e tem como afluentes o rio Roncador, o córrego da Taquara e os canais de Santo Antônio e Mato Alto. Após juntar-se com o rio Inhomirim passa a se chamar rio Estrela até a sua foz, desaguando na Baía de Guanabara (IBG, 2002; SANTOS, 2006).

Assim a sub-bacia do rio Saracuruna integra a bacia do rio Estrela (Figura 1), e está parcialmente inserida nos municípios de Duque de Caxias e Magé, pertencentes à denominada Baixada Fluminense (Região Metropolitana), e no município de Petrópolis (Região Serrana). 

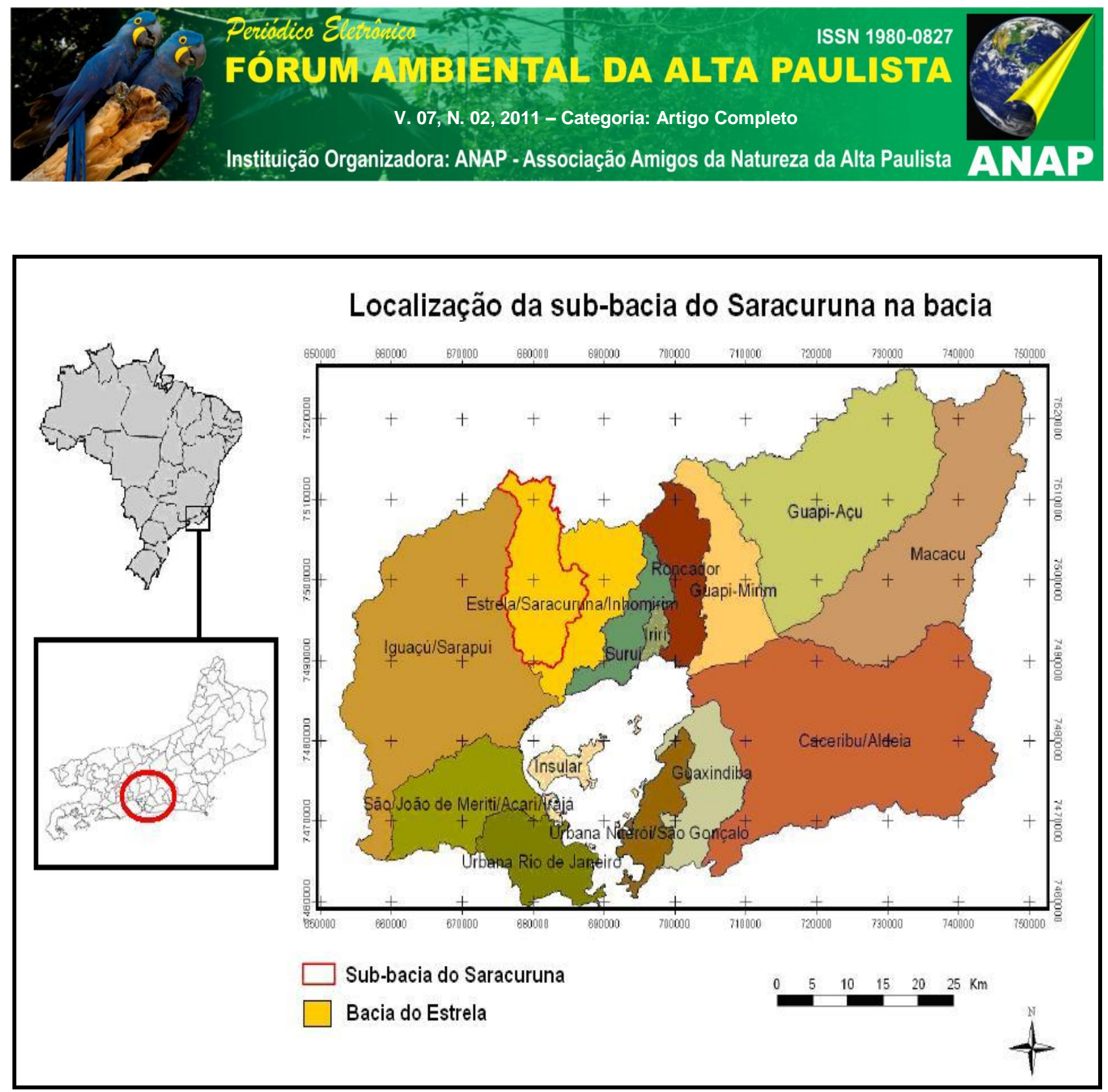

Figura 1 - Mapa de localização da sub-bacia do rio Saracuruna (Adaptado de SANTOS, 2006, p. 19).

Na sub-bacia do rio Saracuruna observa-se uma diversidade de usos do solo em seu território. Dentre os usos naturais destacam-se as áreas de floresta e mangue, e dentre os artificiais, citam-se as áreas urbanas com ocupação residencial e industrial. Podem ser ainda mencionadas as áreas de pastagem e agricultura.

Segundo o Plano Diretor de Recursos Hídricos da Região Hidrográfica da Baía de Guanabara, a vegetação nativa na sub-bacia em questão encontra-se expressiva apenas no alto curso dos rios e com remanescente em médio curso. Ao longo das margens dos rios e em encostas observam-se processos de escorregamentos, com ocupações irregulares, favorecendo a ocorrência de impactos, como deslizamentos e inundações (CONSÓRCIO ECOLOGUS-AGRAR, 2005). 


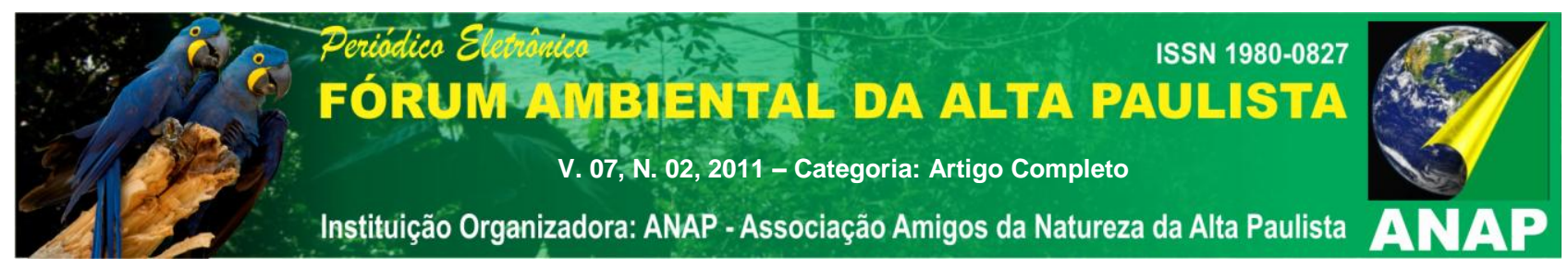

\subsection{REFLEXÕES SOBRE A AGENDA 21 LOCAL DA SUB-BACIA DO SARACURUNA - RJ}

\subsubsection{Temas e atores sociais envolvidos}

Os prováveis temas prioritários, vinculados a uma futura Agenda 21 Local da subbacia do Rio Saracuruna - RJ podem ser estruturados a partir de quatro pilares básicos norteadores: Meio Ambiente; Desenvolvimento Social; Planejamento, Gestão e Política; e Economia e Sustentabilidade.

Com base na apresentação e justificativa da área de interesse para construção de uma Agenda 21 Local, podem ser elencados temas interligados para discussão em fórum, observando vínculo com os pilares anteriormente citados: Apoio às atividades rurais; Direcionamento do crescimento urbano; Gestão de Unidades de Conservação; Articulação intermunicipal; Exploração da biodiversidade; Proteção às áreas de mangue; Áreas de lazer (arborização) na sub-bacia; Transportes urbanos e vias públicas; Educação ambiental; Limpeza urbana; Atividades econômicas na bacia / Geração de emprego; Reflorestamento; Gestão de Áreas de Preservação Permanente; Ocupação de moradias em Áreas de Preservação Permanente; Conservação da mata ciliar; Direito à propriedade e adequação de usos; Direito à habitação; Acesso à infraestrutura sanitária; Enchentes; Canalização de rios; Poluição industrial; Cultivo e poluição do solo / rios; Aterros sanitários; Despejo residencial de resíduos sólidos: lixo nos rios; Erosão às margens de rios; Assoreamento dos rios.

Os atores sociais com potencial de envolvimento no processo de construção e desenvolvimento de uma futura Agenda 21 Local da sub-bacia do rio Saracuruna são: 


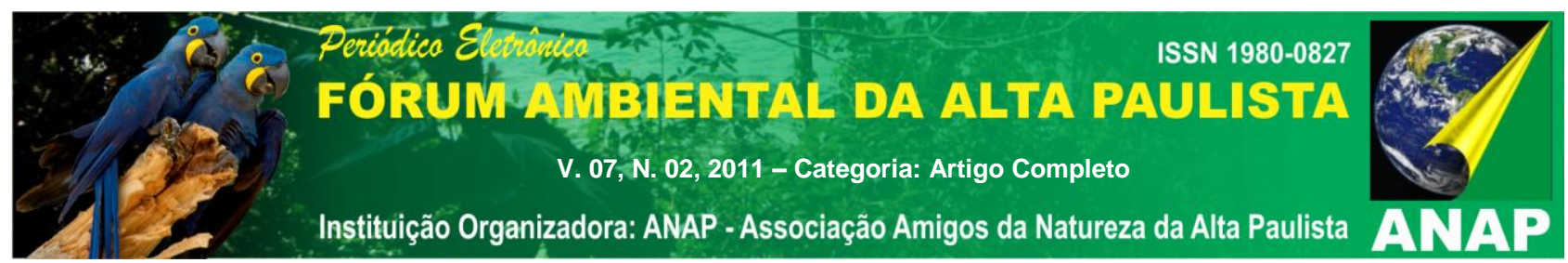

- Lideranças comunitárias e associações de moradores dos bairros e localidades que integram totalmente ou parcialmente a sub-bacia do Saracuruna, dentre as quais pode-se destacar a "Associação Pró-Melhoramentos de Saracuruna ${ }^{3}$, com ênfase para reivindicações sociais da comunidade;

- Organizações não-governamentais (ONG's) com potencial de atuação em quaisquer dos pilares temáticos da Agenda 21 Local da sub-bacia, tendo como exemplo o "Instituto da Baía de Guanabara - IBG", que possui como objetivos o estudo, a pesquisa e a solução dos problemas ambientais, sociais e urbanos, com prioridade na Região Hidrográfica drenante para a Baía de Guanabara;

- Centros de ensino e pesquisa superior, tais como: a Faculdade de Educação da Baixada Fluminense - FEBF, da Universidade do Estado do Rio de Janeiro (campus da UERJ em Duque de Caxias); o Núcleo Interdisciplinar em Meio Ambiente - NIMA da Pontifícia Universidade Católica do Rio de Janeiro - PUC-Rio, que mantém o projeto "Educação Ambiental em Duque de Caxias" 4.

- Representantes do setor industrial e empresarial: Representação Regional Baixada $1 I^{5}$ da Federação de Indústrias do Estado do Rio de Janeiro - FIRJAN;

- Representantes de propriedades que desempenham atividades rurais na subbacia;

- O Instituto Estadual do Ambiente - INEA - órgão gestor ambiental do Estado do Rio de Janeiro, imbuído da missão de proteger, conservar e recuperar o meio ambiente para promover o desenvolvimento sustentável -, e suas diretorias: Diretoria de Informação e Monitoramento Ambiental; Diretoria de Biodiversidade e Áreas Protegidas; Diretoria de Gestão das Águas e do Território; Diretoria de Recuperação Ambiental;

\footnotetext{
${ }^{3}$ Endereço do blog da Associação: <http://apromesa.blogspot.com/>.

${ }_{5}^{4}$ Página do projeto: <http://www.nima.puc-rio.br/index.php/projetos/educacao-ambiental/duque-de-caxias>.

${ }^{5}$ Com atuação nos municípios: Duque de Caxias, Paty do Alferes, Miguel Pereira, Belford Roxo, São João de Meriti, Magé, Guapimirim.
} 
- Comitê da Região Hidrográfica da Baía de Guanabara e dos Sistemas Lagunares de Maricá e Jacarepaguá, integrando os municípios de Duque de Caxias e Magé, no âmbito do Sistema Estadual de Gerenciamento de Recursos Hídricos;

- Prefeitura de Duque de Caxias e seus órgãos: Secretaria de Articulação Institucional; Secretaria de Assistência Social e Direitos Humanos; Secretaria de Desenvolvimento Econômico; Secretaria de Educação; Secretaria de Habitação; Secretaria de Meio Ambiente e Agricultura; Secretaria de Obras e Urbanismo; Secretaria de Integração, Segurança Pública e Defesa Civil; Secretaria de Transporte e Serviços Públicos; Secretaria de Trabalho, Emprego e Renda; Fundação para o Desenvolvimento Tecnológico e Social de Duque de Caxias FUNDEC;

- Prefeitura de Magé e seus órgãos: Secretaria de Emprego, Trabalho e Renda; Secretaria de Planejamento; Secretaria de Habitação; Secretaria de Urbanismo; Secretaria de Transporte; Secretaria de Obras; Secretaria de Turismo e Meio Ambiente; Defesa Civil; Secretaria de Educação, Cultura, Esporte e Lazer; Secretaria de Desenvolvimento e Agricultura; Secretaria de Desenvolvimento e Assistência Social;

- Prefeitura de Petrópolis e seus órgãos: Secretaria de Obras; Secretaria de Meio Ambiente e Desenvolvimento Sustentável; Coordenadoria de Defesa Civil; Secretaria de Ciência e Tecnologia, Desenvolvimento Econômico e Agricultura; Secretaria de Planejamento e Urbanismo; Secretaria de Esportes e Lazer; Secretaria de Educação; Secretaria de Trabalho, Assistência Social e Cidadania; Secretaria de Segurança Pública; Secretaria de Habitação.

\subsubsection{Tema Específico}




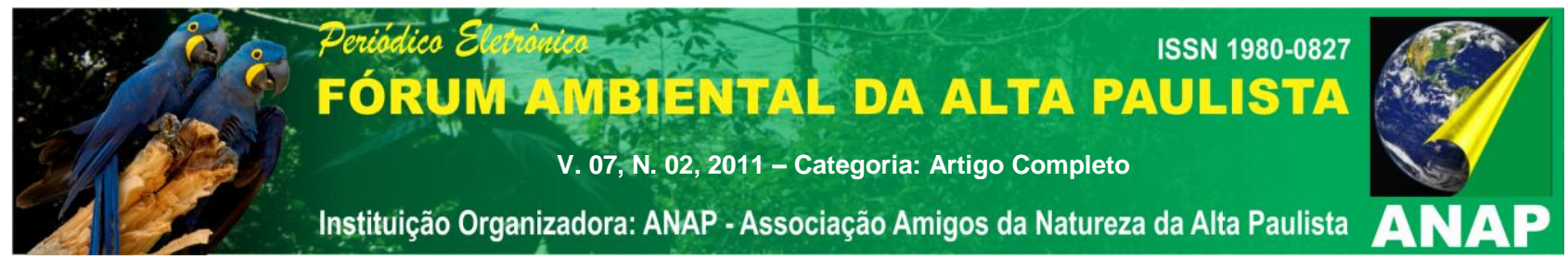

Como visto a sub-bacia do rio Saracuruna conta com áreas de floresta e áreas de ocupação de baixa, média e alta densificação urbana, com a presença, inclusive, de ocupações irregulares. Com isso, a discussão e avaliação de Áreas de Preservação Permanente (APP's) na sub-bacia tornam-se medidas em potencial para a "conservação do meio ambiente" e para o "monitoramento e controle ambiental" ${ }^{6}$.

Segundo o Código Florestal (BRASIL, 1965), atualmente em revisão, as APP's configuram faixas territoriais, legalmente protegidas, classificadas em diversas categorias com função ambiental de preservar o meio físico-natural (os recursos hídricos, a paisagem, a estabilidade geológica, a biodiversidade, o fluxo gênico de fauna e flora, proteger o solo), além de assegurar a qualidade vida das populações humanas.

Nowatzki et al. (2009) apontam que, ao se estudar as APP's dentro de uma subbacia hidrográfica, é importante que se entenda como o homem, com a sua dinâmica social, se apropriou destes espaços e os transformou por meio de seu trabalho, alterando os fluxos de matéria e energia no ambiente que ele se adequou.

Quando se discute o tema Assoreamento dos rios, por exemplo, deve-se atentar para o fato de que esta é uma dinâmica que ocorre no interior de uma sub-bacia / bacia hidrográfica ou mesmo de uma região hidrográfica, ou seja, tudo começa com a erosão intensificada pelo mau uso do solo, ou da errônea localização das atividades humanas causadoras destes impactos.

Neste sentido, a avaliação de APP's em sub-bacias hidrográficas dá um excelente subsídio para o planejamento territorial. A partir disso pode-se propor medidas prioritárias à recuperação das APP's mais degradadas e manutenção das mais preservadas.

Temas relacionados às Áreas de Preservação Permanente vêm sendo inseridos na pauta de Agendas 21 Locais, em nível municipal e regional, com ênfase para a gestão. Rosa (2007, p. 13), identificou na Agenda 21 Local do município de Araucária-PR um grupo temático relacionado à gestão de recursos naturais, no qual as discussões estão baseadas na "análise e reformulação (quando necessário) das políticas de conservação adotada pelo município (unidades de conservação, áreas de preservação permanente)", além da "elaboração de programas e ações de educação ambiental e propostas de

\footnotetext{
${ }^{6}$ Linhas de pesquisa do Doutorado Multidisciplinar em Meio Ambiente da Universidade do Estado do Rio de Janeiro - PPG-MA/UERJ.
} 


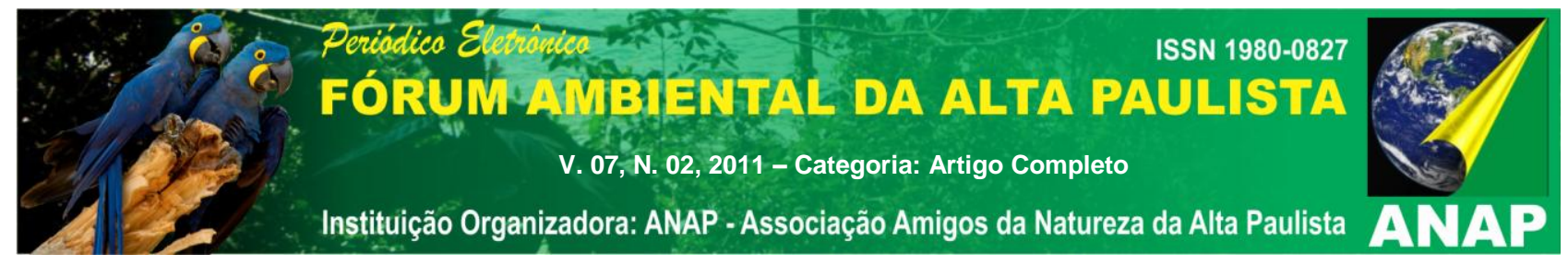

modernização e adequação administrativa na área de controle, fiscalização e monitoramento ambiental".

Recorrendo ao documento referente às Planilhas de Consolidação Municipal da Agenda 21 Local do Município de Magé, vinculado ao Complexo Petroquímico do Rio de Janeiro (COMPERJ, 2010), atesta-se um grande envolvimento com a questão da ocupação em APP's. Neste, há a proposição de mecanismos para se conter o avanço das construções irregulares nas Áreas de Preservação Permanente.

No documento supracitado constam os seguintes problemas relacionados ao tema: Falta de políticas públicas para os moradores de área de risco (ocupação de encostas e manguezais); Ausência de plano de emergência para áreas de risco, enchentes e deslizamentos; Aumento da população ribeirinha, instaladas em áreas das matas primitivas removidas; Existência de grandes assentamentos humanos sem infraestrutura adequada; Ausência de política municipal para uso do solo e assentamentos.humanos; dentre outros.

Já dentre as potencialidades levantadas (de acordo com o tema) figuram: Disponibilidade de áreas para construção de moradias populares para reassentamento das populações que estão em áreas de risco ou sem moradia; Implementação efetiva do Plano Diretor (versando sobre instrumentos de regulação da ocupação urbana).

Segundo Abirached (2006), nas áreas urbanas e eleitas para a expansão urbana, as diretrizes de uso e ocupação do solo, integradas à legislação ambiental pertinente, devem ser concebidas com séria preocupação quanto à manutenção, no máximo possível, dos corpos de água, evitando alterar as características das APP's, devido a sua importante função(ões) ambiental(ais).

Ainda de acordo com o autor, é justificável a alteração do regime jurídico do uso ocupação do solo nas APP's em casos extraordinariamente especiais. Esta situação pode ocorrer, por exemplo, “com a regularização fundiária e urbanística para fins de garantia de moradia digna para população de baixa inclusão social que ali se assentaram por fatores conjunturais e socioeconômicos diversos" (ABIRACHED, op. cit., p. 80).

$\mathrm{Na}$ sub-bacia do Saracuruna, o tema Ocupação de moradias em Áreas de Preservação Permanente é latente com relação ao rol de temas prioritários. A partir da identificação e cadastro de imóveis nestas faixas pode-se gerar classes de densidade e, em conjunto (a partir da visão de especialistas e não-especialistas), se discutir sobre os 


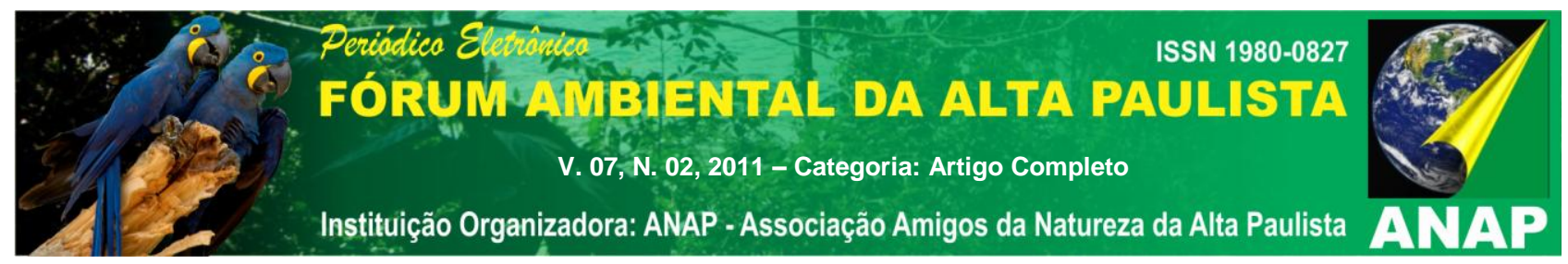

rumos das áreas, envolvendo possibilidades práticas, tais como: remoção de moradias e recuperação total desta vegetação (se possível e viável); intervenções geotécnicas em faixas críticas, tais como as áreas com moradias comprometendo totalmente as margens dos rios (Figura 2); ou regularização fundiária e direcionamento de ações de minimização dos impactos gerados, tal como o despejo de esgoto diretamente nos rios.

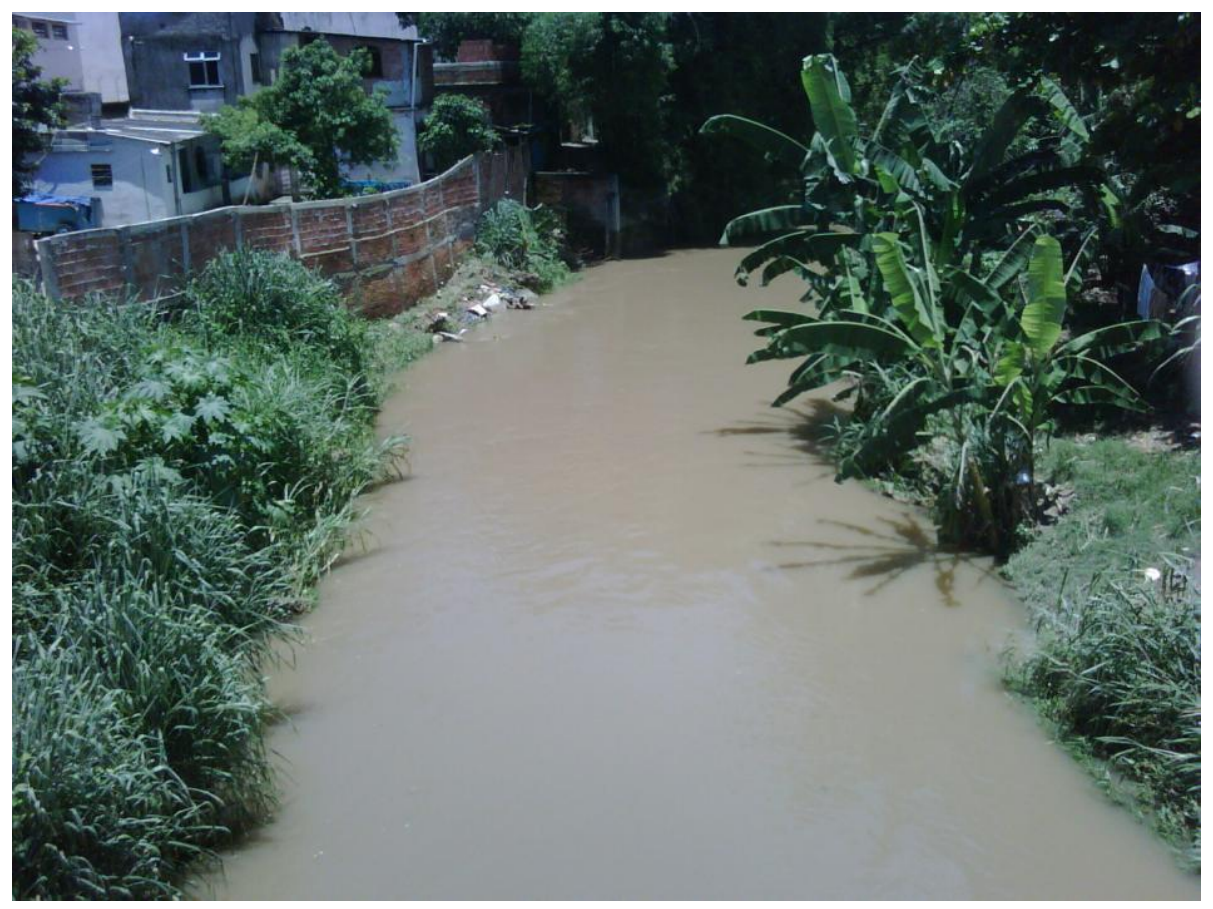

Figura 2 - Ocupação densificada de moradias às margens do Rio Saracuruna - Proximidade de Santa Cruz da Serra. Fonte: Foto de Rodrigo Silva da Conceição (2010).

\subsubsection{Visão dos Especialistas e Não especialistas}

- Especialistas

Segundo o INEA (2010a; 2010b), o processo histórico de ocupação da região da Baixada Fluminense é marcado pela proliferação de loteamentos sem infraestrutura. A ocupação irregular nas margens dos rios ocorre, logicamente, pela ausência de programas habitacionais, assim como pela ausência de controle do uso do solo de forma a impedir a ocupação nas margens dos rios. 


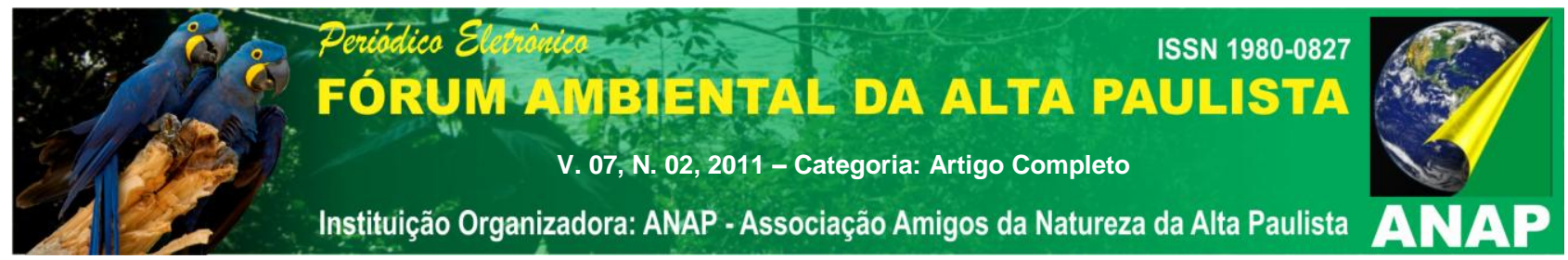

Sem rede de esgotamento sanitário, nem de coleta de lixo adequada, os resíduos são lançados diretamente nos corpos hídricos, provocando o assoreamento que compromete o sistema de vazão das águas. Nos municípios de Duque de Caxias e Magé a maior das inundações ocorre em loteamentos irregulares, localizados em terras baixas, nas proximidades dos rios que cortam estes municípios.

$\mathrm{Na}$ Região Serrana têm se observado, ao longo dos anos, inúmeras tragédias relacionadas aos deslizamentos de terra e inundações, a exemplo das ocorrentes em janeiro de 2011. O município de Petrópolis conta com diversas categorias de APP destacando-se as de margem de rios e as de altas declividades, as quais, em alguns casos, abrigam ocupações desordenadas. Tal situação favorece a perda da função ambiental destes espaços, a partir da retirada da vegetação e exposição das populações aos riscos, descaracterizando-as como tal (CREA-RJ, 2011; MMA, 2011).

O Plano Diretor pode definir critérios para a adequada utilização em áreas com função ambiental, inclusive determinando regras condizentes com as necessidades ambientais da bacia hidrográfica. Sobretudo aplicando as regras do Código Florestal para as APP's em áreas urbanas, a fim de que possam prestar seus inúmeros serviços ambientais e hidrológicos (ABIRACHED, 2006).

Dentre os municípios que integram áreas da sub-bacia do rio Saracuruna, o município de Duque de Caxias possui seu Plano Diretor disponibilizado, revisto e atualizado, através de sua câmara municipal (DUQUE DE CAXIAS, 2006).

A análise do capítulo I, referente à política ambiental, deste documento, denota a percepção de um quadro em que se almeja o (re)ordenamento territorial a partir da compatibilização do atendimento às normas ambientais (vinculadas aos recursos hídricos e florestas) com o direito à habitação. O risco social e ambiental emerge como o desencadeador da proposta de remanejamento da população. $O$ capítulo reforça ainda 0 apoio ao desenvolvimento de um Plano de Ações da Agenda 21 Local.

Em relação à apropriação da legislação e definição estratégica de APP's, o Plano analisado contempla diretrizes absorvidas da legislação federal (Código Florestal). No entanto, é assegurado o uso das APP's ao longo dos corpos d'água da cidade para a implantação de infraestrutura urbana com objetivo de isolamento destas áreas, como uma medida estratégica, sendo então uma possibilidade viável, desde que garantida a preservação de cobertura vegetal que assegure o cumprimento dos objetivos das APP's. 


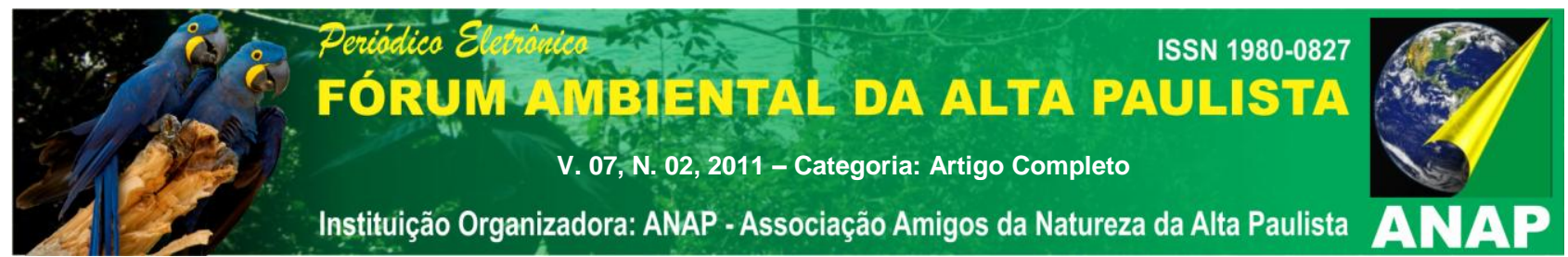

O Plano Diretor de Magé encontra-se ainda em tramitação. Porém, o documento referente à Avaliação final ao Plano Diretor do referido município não traz nenhuma informação diretamente relacionada a diretrizes ou estratégias para as faixas destinadas às APP's (FUNDAÇÃO BENTO RUBIÃO, 2011).

O município de Petrópolis contém em seu Plano Diretor, em processo de atualização e defesa de emendas, algumas considerações pertinentes às APP's. Dentre as diretrizes setoriais ligadas à habitação, consta a inibição de novas ocupações irregulares em áreas impróprias como as APP's, áreas de risco e áreas públicas, evidenciando um compromisso de atuação direta sobre as pressões relacionadas ao aumento da ocupação residencial. $O$ documento supracitado garante ainda que não serão passíveis de parcelamento, edificação ou utilização compulsórios, os imóveis que se encontrem em APP's (PETRÓPOLIS, 2011).

- Não especialistas

A visão de não especialistas sobre o tema Ocupação de moradias em Áreas de Preservação Permanente é fundamental para a discussão participativa e justa do mesmo. Segundo Castro e Negreiros (2010), o cidadão estará mobilizado a participar da gestão do seu ambiente, quando ele realizar pessoalmente que vive, trabalha e se locomove dentro de um sistema ambiental e que é parte deste sistema uma vez que recebe, em sua vida cotidiana, os impactos dos desequilíbrios ambientais locais e que desencadeia outros tantos desequilíbrios ambientais.

Atualmente, com o advento da Internet e criação de grupos virtuais, pode-se agregar a visão de especialistas e não-especialistas de qualquer área de interesse para implementação de discussões. A Rede Brasileira de Agendas 21 Locais - REBAL possui uma grande diversidade de fóruns de discussão, inclusive do município de Duque de Caxias $^{7}$.

Neste fórum virtual, podem ser encontradas discussões acerca de temas diversos. Com relação ao tema Ocupação de moradias em Áreas de Preservação Permanente,

\footnotetext{
7 Endereço do Fórum da Agenda 21 de Duque de Caxias - RJ: <http://rebal21.ning.com/group/frumdaagenda21deduquedecaxiasrj>.
} 


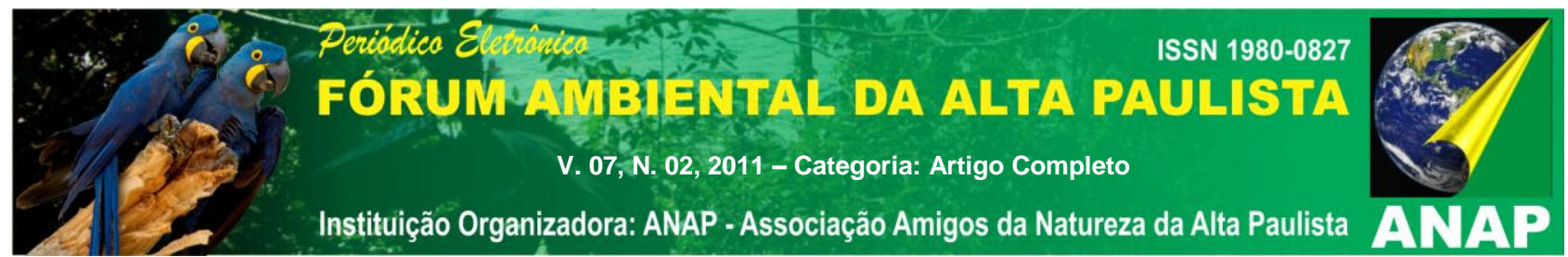

destaca-se a menção de um dos participantes quanto à (in)eficácia da política habitacional no município de Duque de Caxias, classificando-a como uma "incógnita". O mesmo ainda atesta a necessidade de se fortalecer a sociedade para pressionar o governo.

Em um estudo realizado por Castro e Branquinho (2003), com ênfase em ações extensionistas, foram estruturadas diretrizes gerais para um plano de revitalização ambiental para a micro-bacia hidrográfica do rio Santo Antônio, afluente do Saracuruna, em um modelo que mantém proximidade com uma Agenda 21 Local, subsiando a possibilidade de construção da mesma.

As autoras relatam a identificação de diversos problemas na comunidade assentada na micro-bacia, tais como carência de sistema de abastecimento de água, sistema inadequado de coleta de lixo, poluição dos cursos d'água, além das enchentes, principalmente nas áreas mais baixas da micro-bacia.

Além da visão técnica de especialistas ${ }^{8}$, a identificação da problemática local, a partir do conhecimento da comunidade e de suas demandas, segundo as autoras, foi fundamental para a construção de hipóteses, sob a forma de diretrizes, que orientaram os procedimentos e as ações escolhidas para o alcance dos objetivos almejados.

Durante a prática extensionista realizou-se o Seminário Ambiental da Micro-Bacia do rio Santo Antônio, em uma escola estadual, objetivando a discussão dos problemas sócio-ambientais, neste caso, possíveis temas prioritários; além do incentivo a formação de grupos de agentes ambientais e do início à construção da Agenda 21 local. O seminário contou com a apresentação de relatos de moradores antigos, além de alunos.

Dentre os principais problemas documentados, podem ser citados: carência de fossas sépticas, com conseqüente lançamento de esgoto nos rios e córregos, sem tratamento; carência de coleta de lixo, com a conseqüente deposição nos rios e nas ruas; abastecimento d'água precário; enchentes; desmatamentos; redução da água do rio; mau cheiro; falta de pavimentação nas ruas; erosão; loteamento de terras na beira do rio.

\footnotetext{
${ }^{8}$ Constatam-se inúmeras causas para a ocorrência de enchentes: as pequenas declividades dos terrenos em certos trechos do rio, que levam a redução das velocidades de escoamento da água, o acúmulo de grande volume de lixo, os desmatamentos de encostas e de faixas marginais de proteção, reduzindo a retenção natural das águas das chuvas e aumentando a sedimentação do rio; a ocupação desordenada das margens e do leito do rio por construções que impermeabilizam, estrangulam e poluem, reduzindo a seção transversal do leito do rio e provocando a elevação do nível das águas; os aterros que reduzem a calha do rio e os lixos descartados em suas margens, reduzindo a capacidade de fluxo das águas.
} 


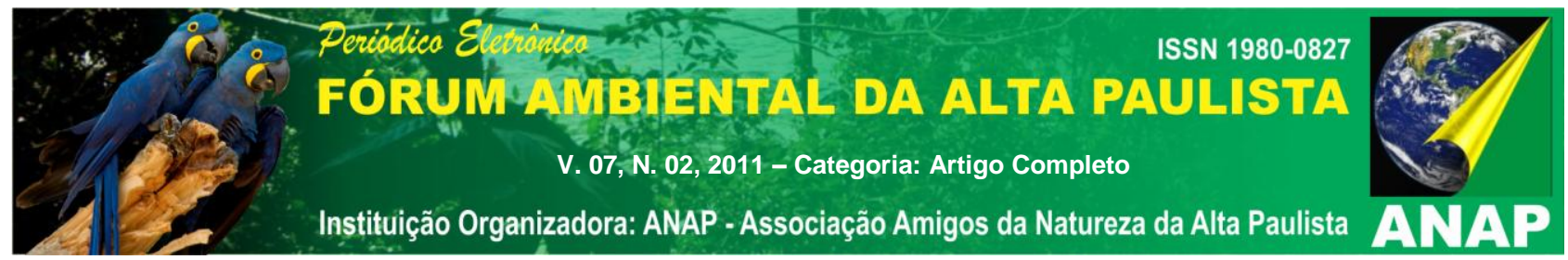

Já dentre as possíveis soluções constam: despoluição e revitalização do rio; proteção e conservação de mananciais (rios e nascentes); reflorestamento nas nascentes do rio santo Antônio com implementação de um Programa de Reflorestamento de suas margens; cobrança de obras de saneamento e coleta de lixo regular aos órgãos públicos municipais; pavimentação das ruas; urbanização regulamentada; dentre outros.

\section{CONCLUSÃO}

A reflexão sobre uma futura Agenda 21 Local da sub-bacia do Rio Saracuruna - RJ promoveu um interessante exercício de fixação dos preceitos deste instrumento aplicado em âmbito local, favorável à integração de temas e atores sociais.

A diversidade ambiental nesta sub-bacia revela uma gama de problemáticas e potencialidades, culminando em uma riqueza de possibilidades a serem consideradas no levantamento dos temas prioritários de discussão, com ênfase para questões relacionadas às Áreas de Preservação Permanente.

Por fim, a visão dos especialistas e não especialistas levantadas com relação ao tema selecionado - "Ocupação de moradias em APP's" -, dimensiona a complexidade da questão. Porém, antes de tudo, atesta a importância e necessidade da comunicação entre os diversos atores envolvidos, para que os interesses coletivos e individuais possam ser pesados e equilibrados.

\section{REFERÊNCIAS}

ABIRACHED, C. F. A. O papel do município no planejamento integrado e na gestão participativa do território da bacia hidrográfica. In: KUSTER, A. HERMANNS, K. (Orgs.). Agenda 21 Local: gestão participativa de recursos hídricos. Fortaleza: Fundação Konrad Adenauer, 2006.

BRASIL. Lei n. 4.771, de 15 de setembro de 1965. Institui o novo Código Florestal. Disponível em: <http://www.planalto.gov.br/ccivil_03/Leis/L4771.htm>. Acesso em: 14 abr. 2011. 


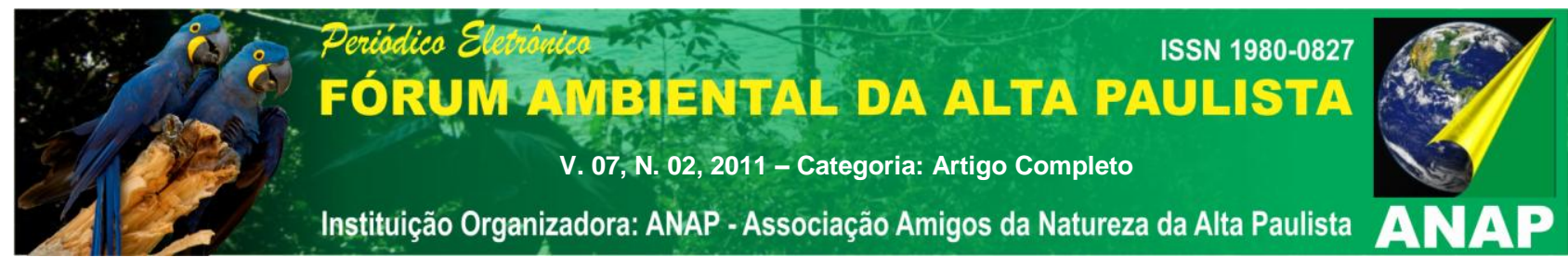

CASTRO, D. M. M.; NEGREIROS, D. H. A preparação da sociedade para a participação na proteção do ambiente - Marco conceitual e experiência do Instituto Baía de Guanabara. In: Fundación Nueva Cultura del Água. Disponível em: <http://www.fnca.eu/fnca/america/docu/1911.pdf>. Acesso em: 02 dez. 2010.

CASTRO, E. M. N. V.; BRANQUINHO, F. T. B. Meio Ambiente e Práticas SócioAmbientais Integradas. In: V SEMPE - Seminário de Metodologia para Projetos de Extensão. Anais... João Pessoa: UFPB, 2003.

CASTRO DA COSTA, T. C. et al. Um indicador de vulnerabilidade para sub-bacias hidrográficas do Estado do Rio de Janeiro. Revista Geografia - v. 17, n. 2, jul./dez. 2008. Londrina: UEL, 2008. 19 p.

COMPERJ - Complexo Petroquímico do Rio de Janeiro. Agenda 21 Local de Magé, Disponível em: <http://www.agenda21comperj.com.br/municipios/mage>. Acesso em: 03 dez. 2010.

CONSÓRCIO ECOLOGUS-AGRAR. Plano Diretor de Recursos Hídricos da Região Hidrográfica da Baía de Guanabara - Síntese. Rio de Janeiro: Ecologus-Agrar, 2005. $190 \mathrm{p}$.

CREA-RJ - Conselho Regional de Engenharia, Arquitetura e Agronomia do Rio de Janeiro. Relatório Preliminar da Inspeção realizada em áreas de Teresópolis e Nova Friburgo afetadas pelas fortes chuvas: janeiro de 2011. Rio de Janeiro: CREA-RJ, 2011. 88 p.

CUNHA, L.H.; COELHO, M. C. N. Política e gestão ambiental. In: CUNHA, S. B. da; GUERRA, A. J. T. (Org.). A questão ambiental: diferentes abordagens. Rio de Janeiro: Bertrand Brasil, 2003. p. 43-76.

DUQUE DE CAXIAS. Câmara Municipal. Lei Complementar n.. 01, de 31 de Outubro de 2006. Duque de Caxias: Câmara Municipal, 2006.

FUNDAÇÃO BENTO RUBIÃO. Avaliação final ao Plano Diretor de Magé. Disponível em: $<$ http://www.observatoriodasmetropoles.ufrj.br/mage.pdf>. Acesso em: 16 jun. 2011. 66 p. 


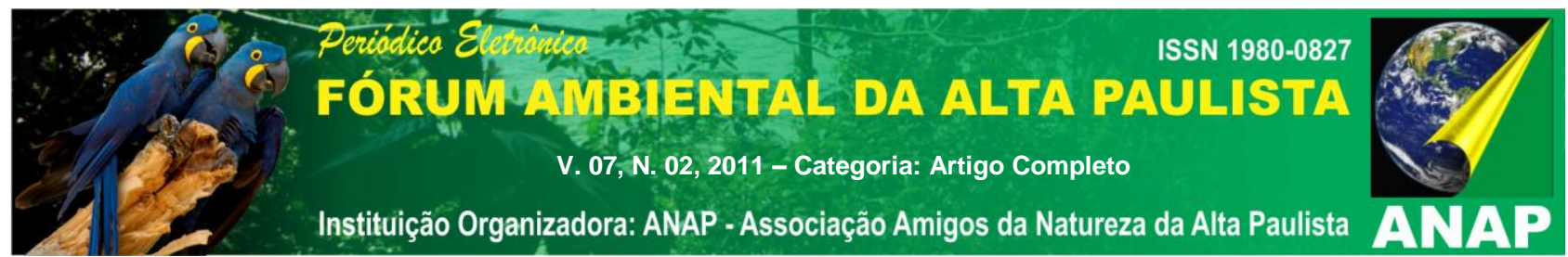

IBG - Instituto da Baía de Guanabara. Nossos Rios. IBG: Niterói, 2002. 34 p.

INEA - Instituto Estadual do Ambiente. Faixa Marginal de Proteção (2010a). Disponível em: <http://www.serla.rj.gov.br/recursos/fmp.asp>. Acesso em: 27 abr. 2010.

INEA - Instituto Estadual do Ambiente. Projeto Iguaçu (2010b). Disponível em: <http://www.serla.rj.gov.br/mais/pj_iguacu.asp>. Acesso em: 02 dez. 2010.

MMA - Ministério do Meio Ambiente. O que é Agenda 21? Disponível em:

$<$ http://www.mma.gov.br/sitio/index.php?ido=conteudo.monta\&idEstrutura=18\&idConteudo $=597>$. Acesso em: 02 de dez. 2010.

MMA - Ministério do Meio Ambiente. Relatório de inspeção: Área atingida pela tragédia das chuvas Região Serrana do Rio de Janeiro. Brasília: MMA, 2011. 85 p.

NOWATZKI, A.; DE PAULA, E. V.; SANTOS, L. J. C. Delimitação das Áreas de Preservação Permanente e avaliação do seu grau de conservação na Bacia Hidrográfica do Rio Sagrado (Morretes/PR). In: XIII Simpósio Brasileiro de Geografia Física Aplicada. Anais... Viçosa: UFV, 2009. $18 \mathrm{p}$.

PETRÓPOLIS. Câmara Municipal. Minuta do Projeto de Lei do Plano Diretor do Município de Petrópolis. Petrópolis: Câmara Municipal, 2011.

ROSA, A. A Agenda 21 como instrumento de gestão pública democrática participativa: A experiência de Araucária/PR. In: II Seminário sobre Sustentabilidade. Anais... Curitiba: Centro Universitário Franciscano - FAE, 2007.

SANTOS, W. A. Caracterização GeoAmbiental da bacia hidrográfica do rio Saracuruna - RJ: Planejamento e Gestão. 2006, 213f. Dissertação (Mestrado em Geografia) - Curso de Pós-Graduação em Geografia, UFF. Niterói, 2006. 